\title{
Valorização da ergonomia em graduação de arquitetura no Brasil
}

\author{
Appreciation of ergonomics in architecture graduation in Brazil
}

\author{
MARCELLA LÔBO \\ Mestranda em Design, UFPE, PPGDESIGN, marcellavlobo@gmail.com
}

VILMA VILLAROUCO

Doutora em Engenharia, UFPE - PPGDESIGN/PPERGO, UFC - PPGAU+D, vvillarouco@gmail.com

LAURA MARTINS

Doutora em Arquitetura, UFPE, PPGDESIGN, PPERGO, LABERGO, bmartins.laura@gmail.com

\section{RESUMO}

Este artigo aborda aspectos do estudo da disciplina de ergonomia no curso de arquitetura ofertado pelas universidades públicas do Brasil, a fim de apresentar a relação entre a oferta dos cursos ao longo do país e a disciplina em questão. Como método avaliativo, foram analisados dados quantitativos fornecidos pelo MEC e a interpretação de informações obtidas nos respectivos portais institucionais, gerando tabelas e gráficos comparativos que demonstram a pequena valorização da ergonomia nos cursos de arquitetura no país além da não obrigatoriedade do ensino na maioria das universidades.

PALAVRAS-CHAVE: ergonomia, arquitetura, universidades públicas do Brasil, valorização da ergonomia, disciplina obrigatória.

\section{ABSTRACT}

This article presents the study aspects of this discipline at architecture courses offered by the Public Universities of Brazil, in order to demonstrate the relationship between the course offer in Brazil and this subject. As an evaluative method, quantitative data used by MEC were analyzed and interpreted with information founded at institutional portals, generating comparative tables and graphs that demonstrate a little appreciation of ergonomics in architecture courses in the country beyond the non compulsory study in most universities.

KEYWORDS: ergonomics, architecture, public universities of Brazil, valuation of ergonomics, compulsory course. 


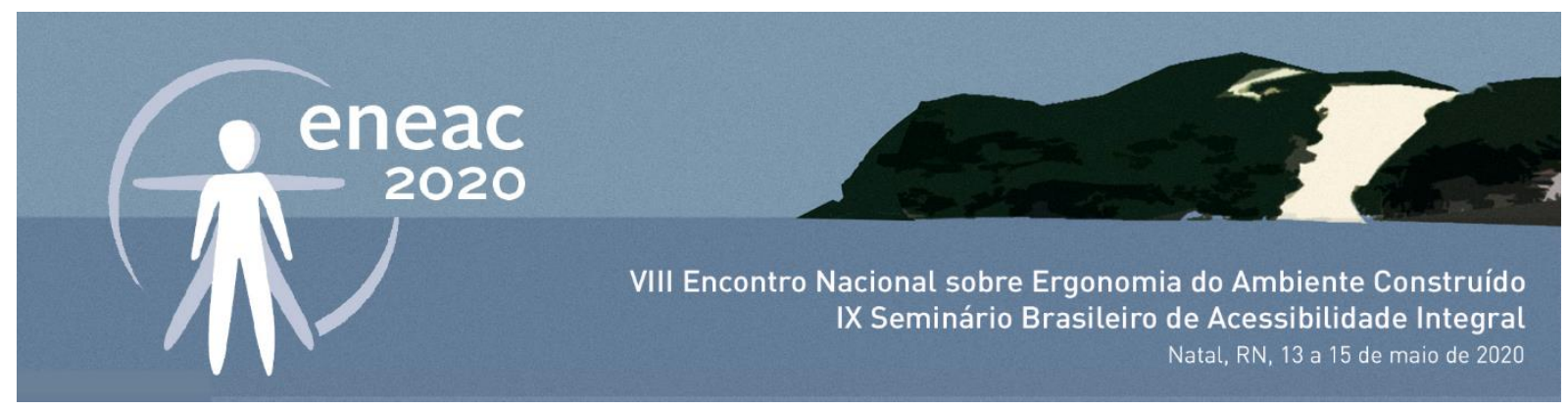

\section{INTRODUÇÃO}

Esta pesquisa buscou avaliar os dados quantitativos fornecidos pelo MEC na Sinopse Estatística para a Educação Superior, apresentando os números de instituições ao longo do ano de 2018 no Brasil (última tabela disponibilizada até o presente momento). Foram levados em consideração os dados relacionados a instituições universitárias públicas, a fim de gerar uma interpretação acerca da valorização do estudo da ergonomia nos cursos de arquitetura oferecidos pelo governo federal para formação de profissionais.

A cronologia de estudo da ergonomia no Brasil tem início na década de 60 (século XX), através do professor Sergio Penna Kehl, no curso de Engenharia de Produção da Escola Politécnica de São Paulo. Desde então, vem se expandindo em diversas áreas de estudo, disseminando sua multidisciplinaridade e tornando-se uma ciência de caráter essencial na construção de inúmeros especialistas.

"Kenneth Frank Hywel" define em 1949 a Ergonomia como "o estudo da relação entre o homem e o seu ambiente de trabalho", oficializada com o surgimento da 1a sociedade de ergonomia, a Ergonomic Research Society. Segundo "Moraes e Soares" (1989), as primeiras experiências relacionadas a ergonomia no Brasil, foram implementadas sem aplicações práticas, inicialmente explorando seus conceitos, em associação ao design, à arquitetura e às engenharias, enfatizando seu significado para os cursos explorados.

A International Ergonomics Association (IEA) anuiu, desde o ano 2000, a seguinte definição oficial:

A Ergonomia (ou Fatores Humanos) é uma disciplina científica relacionada ao entendimento das interações entre os seres humanos e outros elementos ou sistemas, e à aplicação de teorias, princípios, dados e métodos a projetos a fim de otimizar o bem-estar humano e o desempenho global do sistema. Os ergonomistas contribuem para o planejamento, projeto e a avaliação de tarefas, postos de trabalho, produtos, ambientes e sistemas de modo a torná-los compatíveis com as necessidades, habilidades e limitações das pessoas (IEA, 2000).

Dentro da legítima significância do estudo da ergonomia, viu-se a necessidade de posicionar qual a sua relevância na formação de graduandos em arquitetura do ensino público nacional e como ela vem sendo explorada pelas instituições vigentes?

Observados dados do governo federal para o ensino superior, a pesquisa apresentou como objetivo geral indicar a relação entre a oferta dos cursos ao longo do país e a disciplina em questão confrontando a importância do estudo da ergonomia a partir da análise desses quantitativos. Os objetivos específicos dessa avaliação são: i) gerar uma leitura do quadro de ensino superior da arquitetura no Brasil; ii) abordar aspectos institucionais de grade curricular dos cursos; iii) compactar informações e explorar seus valores qualitativos. Explorados todos os recursos, apresenta-se a interpretação atingida dos fatos.

\section{CONSIDERAÇÕES TEÓRICAS}

A Associação Brasileira de Ergonomia (ABERGO) apresenta, como informações atuais, a formação em ergonomia no Brasil existente para nível de pós-graduação, com cursos de especialização ou como 


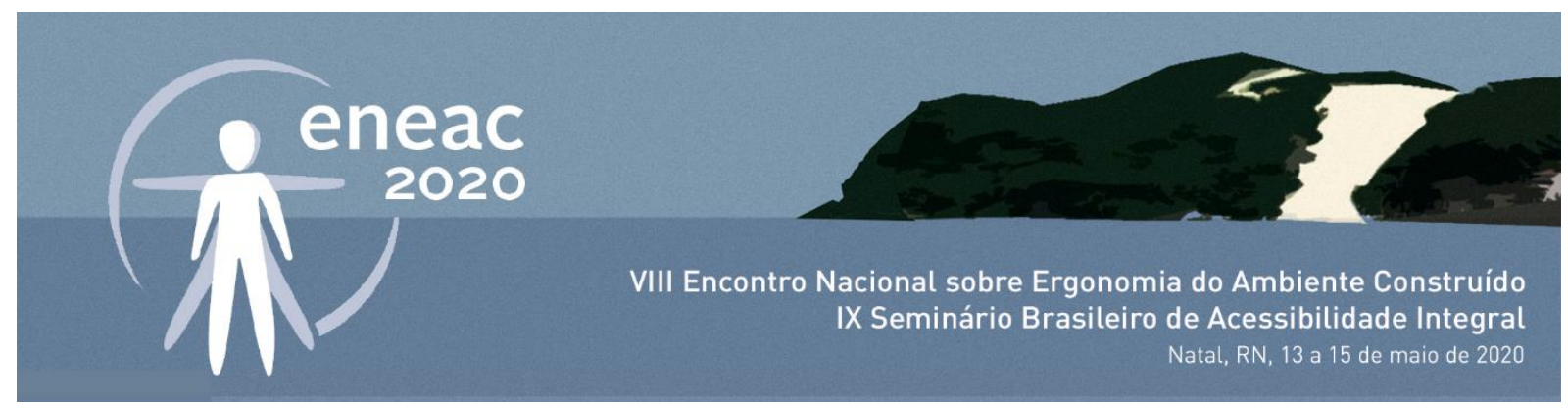

linha de pesquisa (ou área de conhecimento) de grandes áreas como design, arquitetura e engenharia. Apesar dos aspectos apresentados pela associação, identifica-se que a partir de 2011, o Mestrado Profissional em Ergonomia vem sendo ofertado pela UFPE, sendo o pioneiro e único no Brasil.

Como histórico disciplinar da ergonomia, compreendendo seu valor e como se deu sua difusão no campo brasileiro, evoca-se aqui o trabalho de "Moraes e Soares" (1989) onde indicam seis aspectos que contribuíram para a propagação dos seus conceitos e conteúdo.

- Inicialmente, na década de 60 (século XX), pelo professor Sergio Penna Kehl no curso de Engenharia de Produção da Escola Politécnica de São Paulo.

- Em seguida, nos anos 70, no curso de Engenharia de Produção do programa de pósgraduação da UFRJ, por Itiro lida.

- Em 1976, a terceira vertente ocorreu graças ao professor Karl Heinz Bergmiller no curso de Desenho Industrial da Escola Superior de Desenho Industrial da UERJ.

- Na década de 70, surgiram ainda estudos relacionados à psicologia ergonômica através dos professores Reinier Rozestraten e Paul Stephaneck no Curso de Psicologia de Ribeirão Preto.

- Ainda no mesmo período, surge a quinta vertente com o professor Franco Lo Preste Seminério que implementa o estudo ergonômico no curso de Psicologia do Instituto Superior de Estudos e Pesquisas Psicossociais da Fundação Getúlio Vargas/RJ, tendo sido também o organizador do 1 ㅇ Seminário Brasileiro de Ergonomia em 1974 e o criador do 1 o curso de Especialização em Ergonomia no Brasil em 1975.

- Por último, a ergonomia foi intensificada através da vinda de Alain Wisner, incentivador de vários profissionais da ergonomia brasileiros, por influência de Franco Lo Preste Seminério.

O crescimento da área foi expressivo sendo hoje encontrados laboratórios e grupos dedicados aos estudos das diversas vertentes da ergonomia. Associando dados quantitativos de grupos de pesquisa em ergonomia no Brasil junto ao CNPq, "Silva e Paschoarelli" (2010) apresentam um quadro relacionando os números evidentes no país. Tendo em destaque um total de 165 grupos de pesquisa relacionados ao estudo da ergonomia. Atualmente esse número quase dobrou.

Observando as áreas relacionadas às pesquisas de ergonomia, encontram-se três áreas de grande destaque no histórico de ensino da ergonomia: Desenho Industrial, Engenharia de Produção e Arquitetura e Urbanismo. Diante de tais fatos, identifica-se a ergonomia como um elemento relevante para os profissionais da arquitetura, visto seu surgimento e sua continuidade na formação dos mesmos. Por isso, é mister apresentar a relevância da mesma na graduação profissionalizante.

O presente artigo buscou atualizar os dados indicados, isolando as variáveis de maior relevância para a composição do seu objetivo final, permanecendo com os elementos relacionados apenas às instituições universitárias públicas e os parâmetros de graduação em arquitetura no Brasil, reformulando o referido estudo.

O total de grupos de pesquisa em ergonomia atualmente é 243 no CNPq (informação obtida no diretório dos grupos de pesquisa em 21/11/2019). Excluídas as instituições de ensino ligado ao nível 


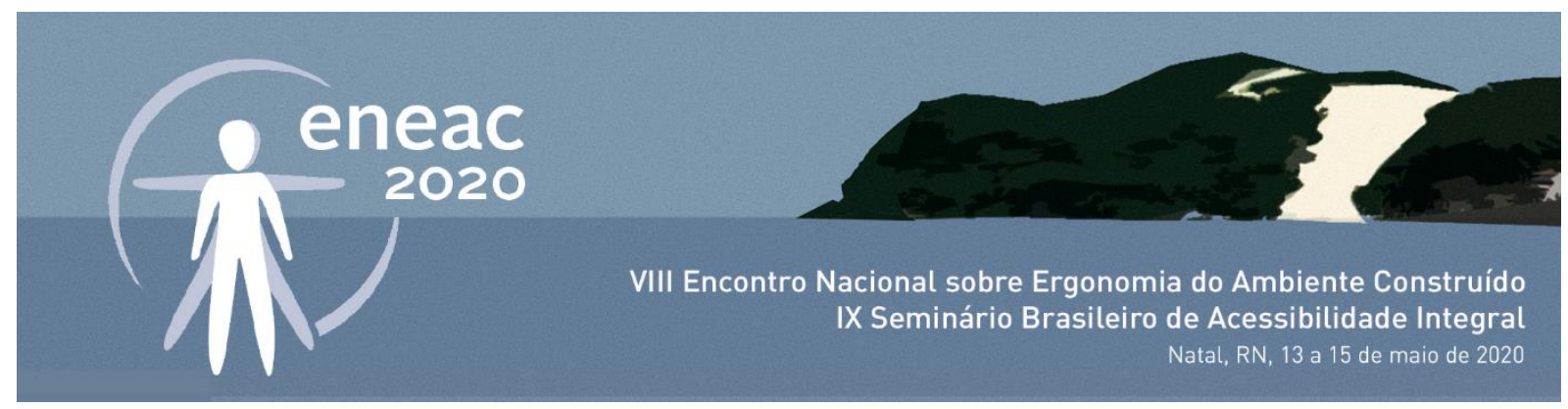

técnico (âmbito não avaliado), foram encontrados 123 registros em universidades federais. Sendo 8 na área de Arquitetura e Urbanismo, área objeto deste trabalho.

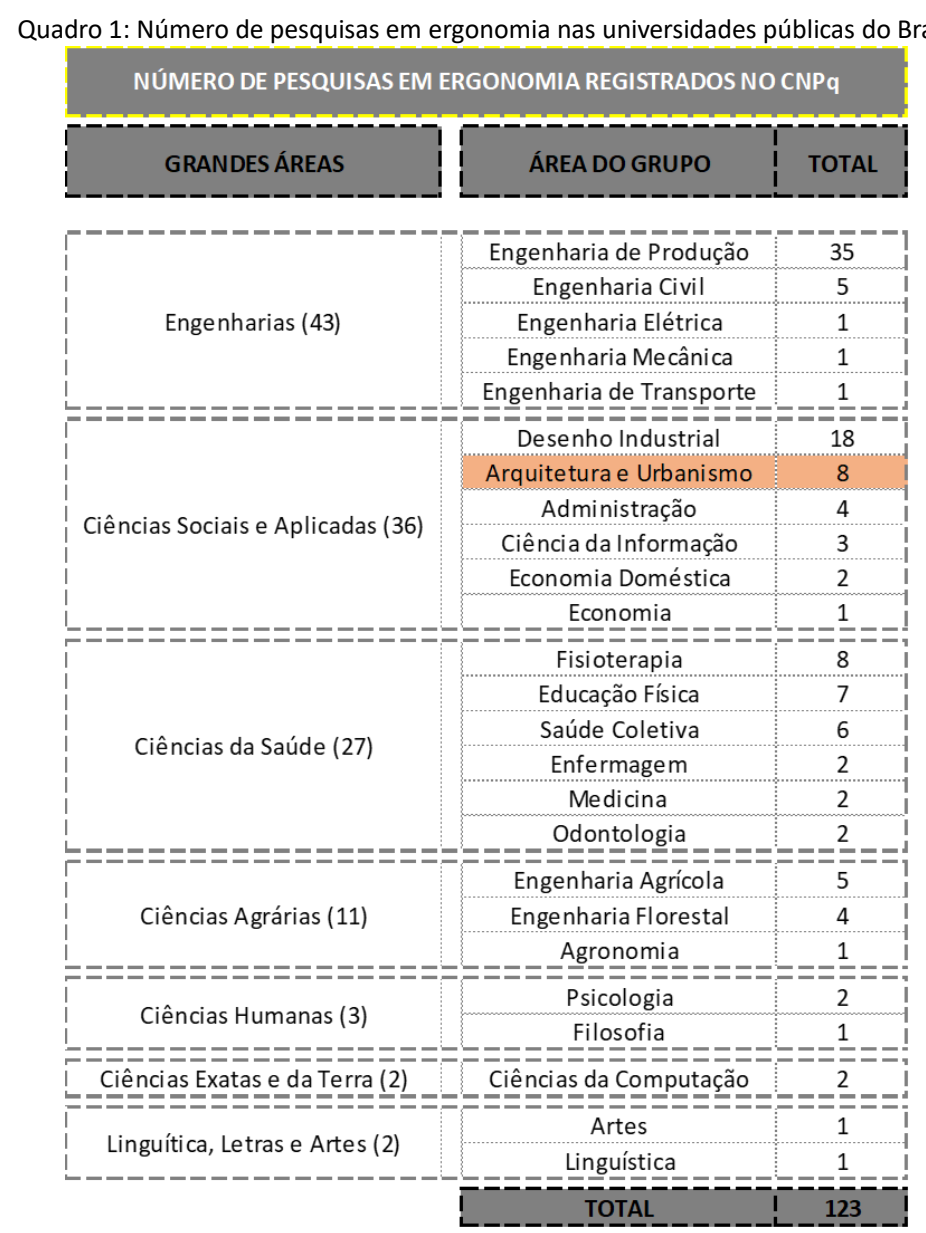

Quando observados os números apresentados, percebe-se a concentração expressiva de grupos em engenharia de produção e design, áreas primárias do estudo da ergonomia, mas menos expressivo na área de arquitetura. Uma vez observada a importância do papel da disciplina na formação desses profissionais, tem-se uma ênfase ainda maior acerca do questionamento apresentado neste trabalho.

\section{CONSIDERAÇÕES METODOLÓGICAS}

Esta pesquisa adotou o método avaliativo de análise de dados através do instrumento fornecido pelo governo federal de síntese do Sistema Nacional de Avaliação da Educação Superior (SINAES) e de informações colhidas nos portais institucionais que disponibilizam atualmente o curso de arquitetura para graduação, correlacionando as grades curriculares com a ênfase dada à disciplina de ergonomia no ambiente de estudo destes profissionais.

Através da tabulação dos dados, foram criadas tabelas de frequência e quantitativos que resultaram em gráficos indicativos da percepção do estudo da ergonomia no meio acadêmico referido. 


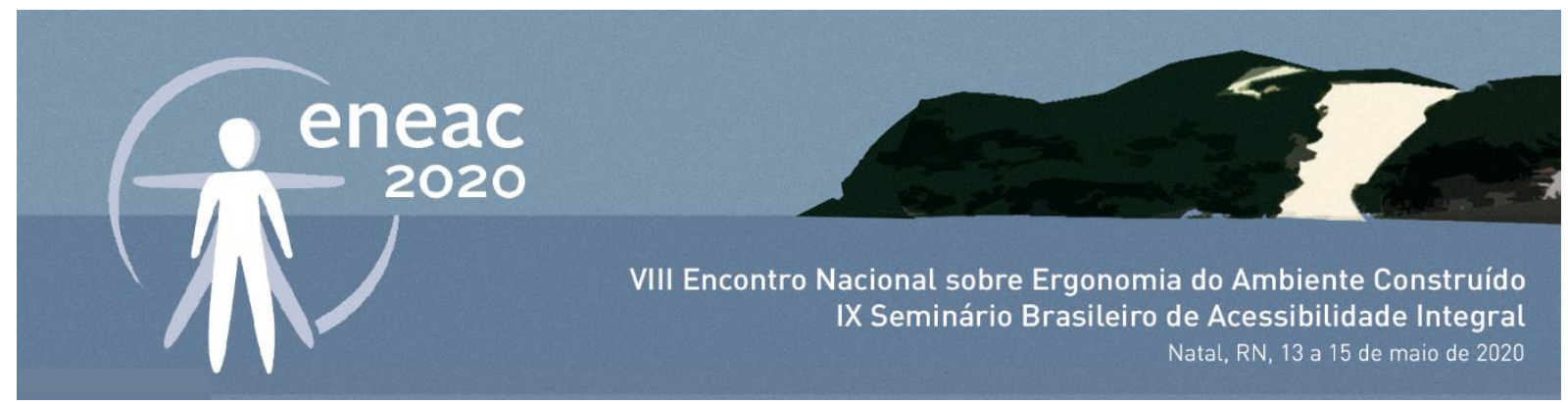

Não foram considerados institutos federais devido ao norteamento dado à pesquisa de caráter profissional interligado à graduação, pois estes estabelecimentos não apresentaram relevância a esta variável, costumando oferecer apenas cursos tecnológicos. Bem como, foram excluídas universidades e faculdades particulares, para que a ênfase possa ser dada ao ensino público.

\section{RESULTADOS E INDICATIVOS}

Os números indicaram um total de 63 universidades públicas no país, dessas 24 contam com o curso de arquitetura, sendo uma relação de $38,1 \%$ das universidades existentes. A disciplina de ergonomia é vista como obrigatória em 21 dos 24 cursos existentes, um total de $87,5 \%$ das grades curriculares ofertadas, em 2 como eletiva e apenas em 1 dos cursos está citada apenas ao longo da ementa de uma disciplina.

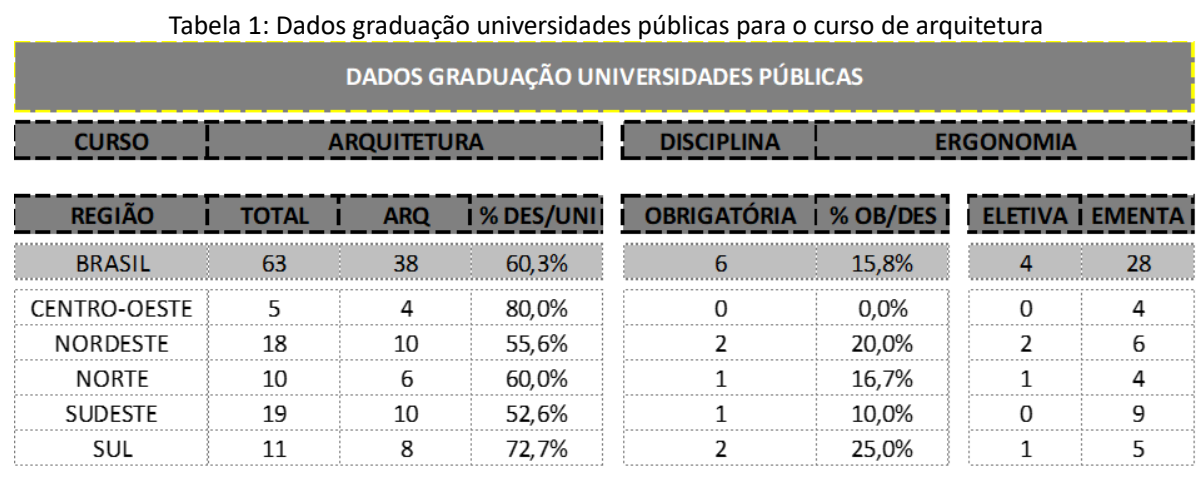

Assim como a pesquisa do Instituto Nacional de Estudos e Pesquisas Educacionais Anísio Teixeira (INEP) é apresentada por regiões, os referidos valores foram analisados partindo do mesmo parâmetro para fins comparativos e indicativos de porcentagem que demonstrem os números apresentados. Como instrumento analítico, os dados foram representados em gráficos.

Gráfico 1: Total de universidades públicas no Brasil



Gráfico 2: Total de cursos de arquitetura no Brasil

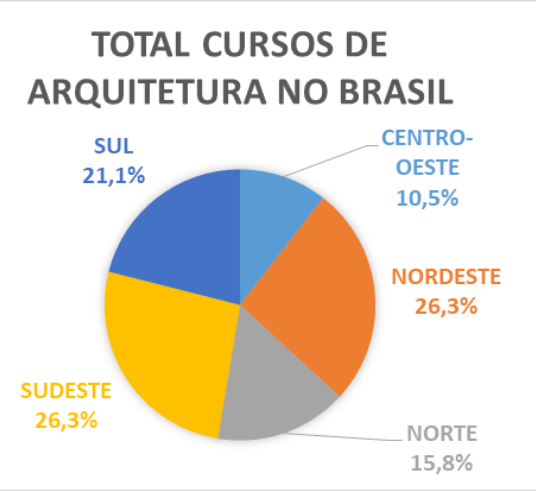




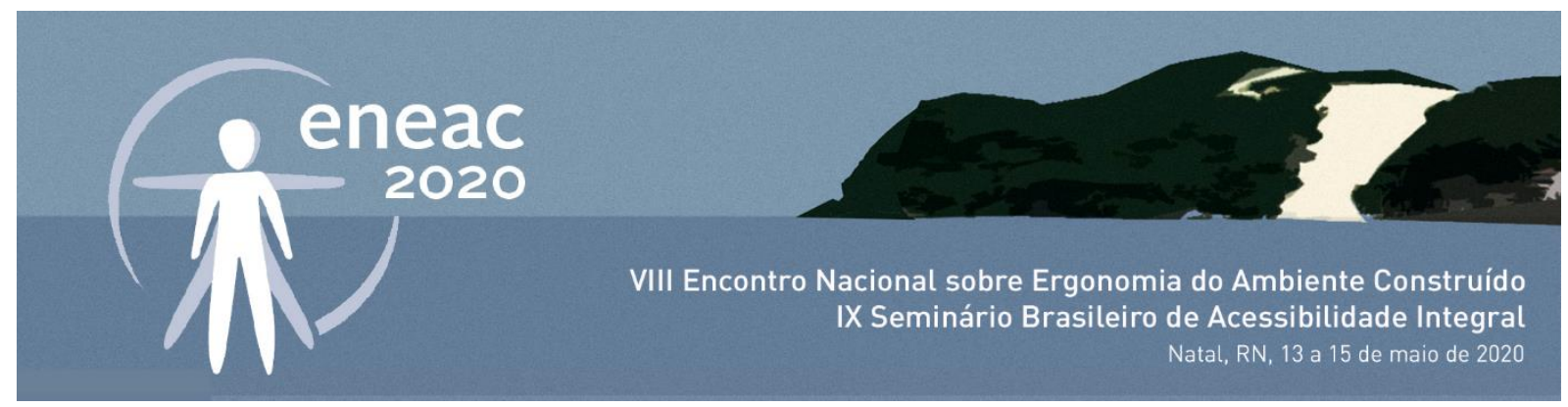

Gráfico 3: Formas de ministrar a ergonomia em cursos de arquitetura no Brasil

FORMAS DE MINISTRAR A

ERGONOMIA EM CURSOS DE ARQUITETURA NO BRASIL

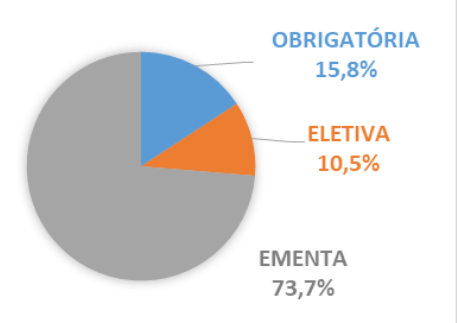

A maior concentração de universidades do país se dá na região Sudeste $(30,2 \%)$, com quantidade de cursos de arquitetura oferecidos em universidades públicas representando $26,3 \%$, percentual igual ao da região Nordeste (26,3\%), que por ter um número de cursos menor que a Sudeste, é proporcionalmente mais significativo. Para a existência da disciplina de ergonomia nestes cursos, registra-se que apenas $15,8 \%$ dos cursos ofertados no Brasil a têm como disciplina obrigatória na grade curricular.

Foram analisados os quantitativos de cursos oferecidos em cada região, como proposto no INEP e constatou-se que a região Centro-Oeste detém o maior índice de universidades com curso de arquitetura no país, visto que $80 \%$ de suas universidades disponibilizam esta graduação para seus estudantes. Seguida pela região Sul com $72,7 \%$, onde o número total de instituições (11) chega a ser quase quatro vezes maior que o número de estados de sua região. A região Sudeste possui a pior taxa de disponibilização do curso ainda que represente o maior número de cursos, pois, possui a maior quantidade de universidades do pais (19), mas em apenas 10 fornece o citado curso.

Gráfico 4: Cursos de arquitetura por região

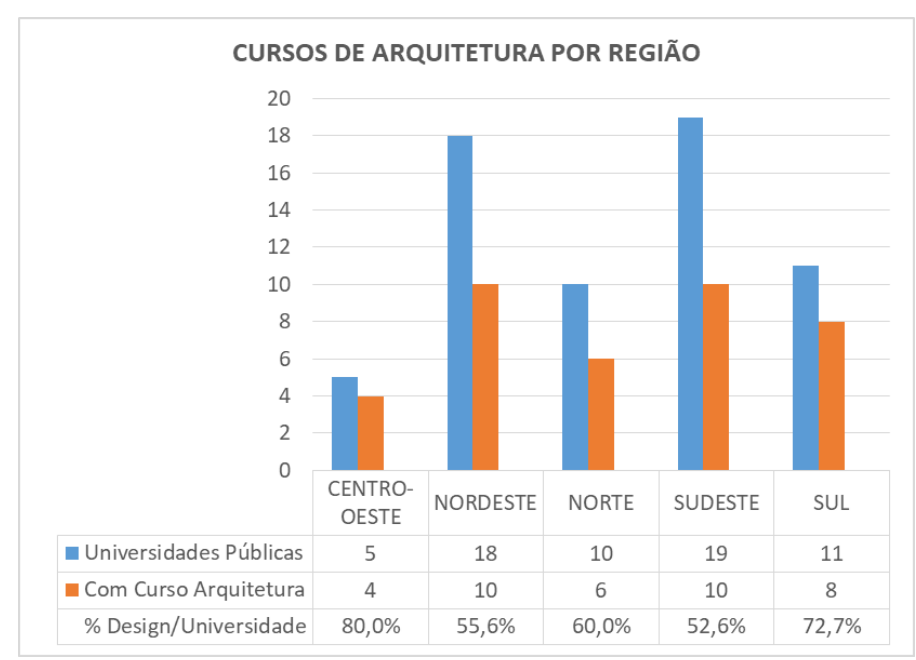

O curso de arquitetura e urbanismo é bastante difundido no território brasileiro apresentando caráter significativo na profissionalização da população, percebendo-se sua relevância para as instituições de ensino superior. 


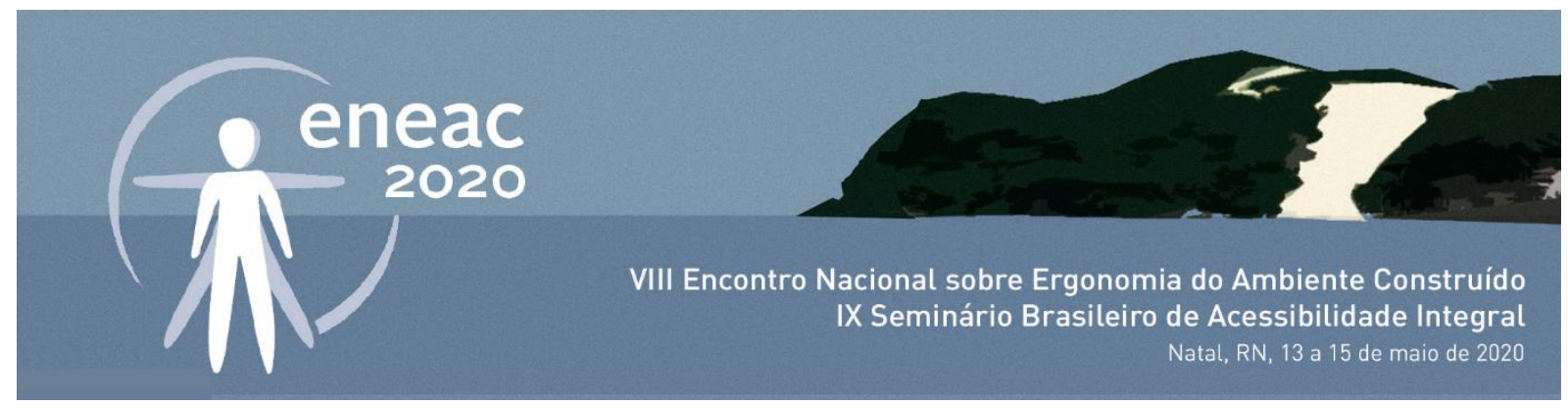

Quando são relacionados os números de cursos oferecidos e a disciplina abordada, tem-se uma disparidade podendo indicar uma desvalorização da mesma, ou mesmo o pouco conhecimento da importância dos seus conteúdos para a formação do estudante de arquitetura, identificado pelo ínfimo índice de sua obrigatoriedade durante o curso em todas as regiões.

Gráfico 5: Ergonomia como disciplina obrigatória

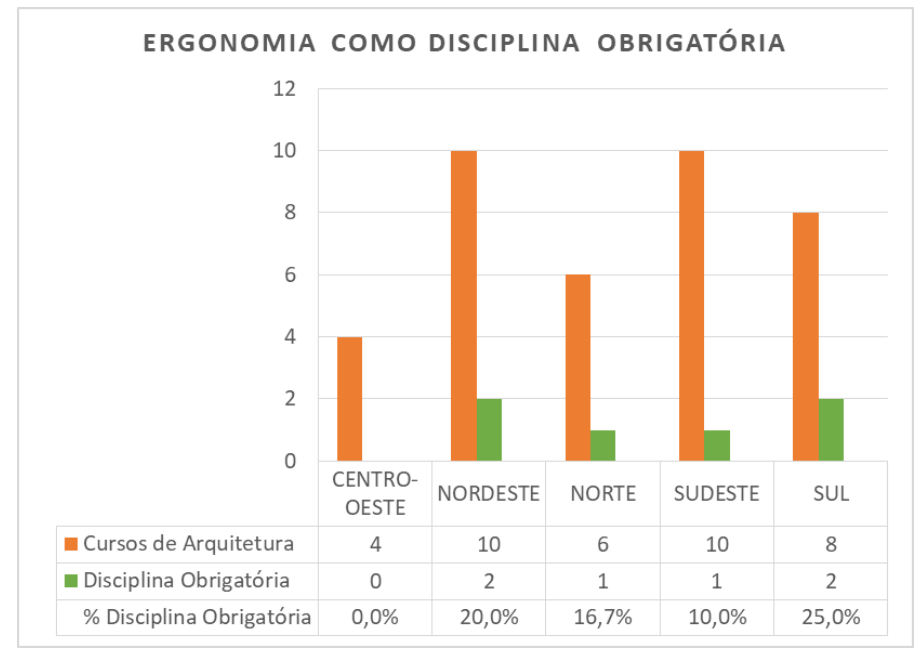

De maneira sintética, observou-se na pesquisa elaborada uma incoerência do elemento variável escolhido como fonte de questionamento e os cursos oferecidos no Brasil. Pode-se inferir que a má exploração da disciplina em cursos de arquitetura é dada devido à desvalorização da mesma por profissionais atuantes no mercado.

Ao longo da pesquisa, alguns dados foram relacionados formando a base para outros quantitativos. Esses valores foram dispostos em uma tabela e a partir de sua exploração, notou-se quatro correspondências interessantes.

- Apenas 7 universidades em todo o país consideram a disciplina como obrigatória na carga horária profissional. Sendo 2 na região Nordeste, 2 na Norte, 1 na Sudeste e 2 na região Sul.

- A Universidade Federal de Pernambuco (UFPE), graças a um momento histórico onde a disciplina, sendo previamente oferecida como eletiva, teve grande busca pelos alunos e obtendo resultados importantes, fruto da atuação do Grupo de Pesquisa em Ergonomia aplicada ao Ambiente Construído das pós-graduações em ergonomia e em design, foi inserida como obrigatória para o graduando na última reforma curricular do curso.

- Em apenas três universidades do Brasil, a disciplina é eletiva, a Universidade Federal do Rio Grande do Norte (UFRN), a Universidade Federal Rural do Semi-Árido (UFERSA) e a Universidade Federal do Rio Grande do Sul (UFRGS).

- Por fim, todas as demais universidades apresentam a nomenclatura ergonomia como ponto a ser abordado ao longo de uma disciplina, aparecendo sua identificação na ementa de uma outra disciplina, que pode ser obrigatória ou não. 


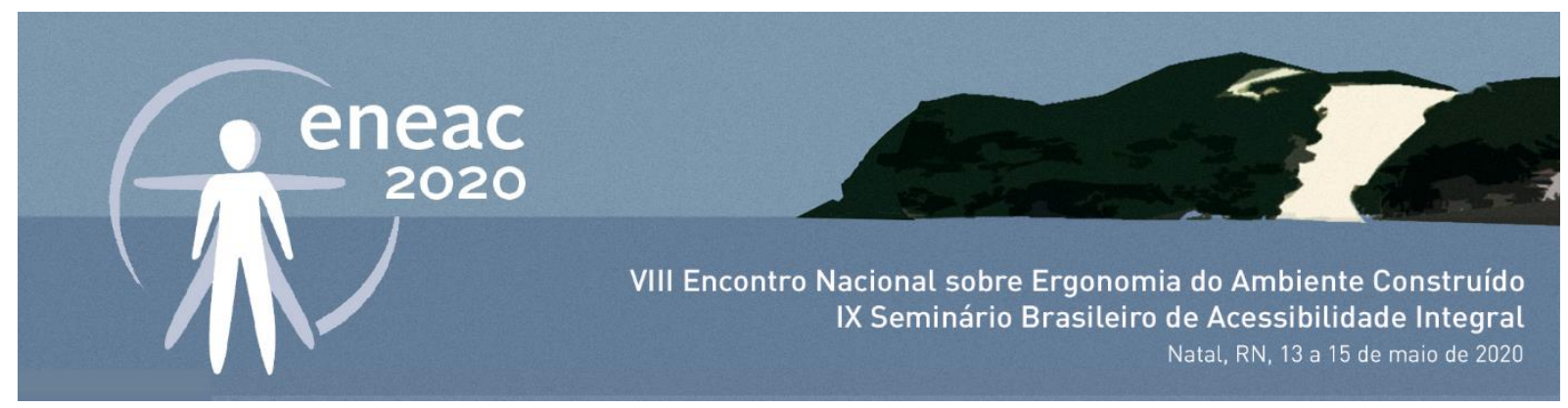

Tabela 2: Cursos de arquitetura e seus dados qualitativos



\section{CONCLUSÕES}

Os dados produzidos e analisados servirão de base para futuras pesquisas relacionadas ao crescimento do estudo da ergonomia no país, contribuindo para formar um comparativo com o ano atual da pesquisa (2019) e seus indicadores qualitativos.

Evoca-se ainda a necessidade de um aprofundamento do estudo para abordar a exploração da disciplina na grade curricular das universidades onde se apresenta como ementa, aumentando significativamente a abordagem da ergonomia como obrigatoriedade na construção do profissional atuante no campo da arquitetura, deixando de ser, somente, uma referência na hora de constituir um projeto de adequação espacial.

O trabalho demonstra, por meio da interpretação dos números obtidos, a necessidade de incentivo para o ensino da ergonomia no curso de arquitetura nas universidades de graduação no Brasil, visto que, a mesma vem sendo meramente compositiva das ementas das disciplinas curriculares. Em sua maioria, as universidades oferecem-na apenas como citações contidas na ementa disciplinar não sendo obrigatórias na formação dos profissionais do ramo.

Agradecemos ao órgão de fomento do Conselho Nacional de Desenvolvimento Científico e 


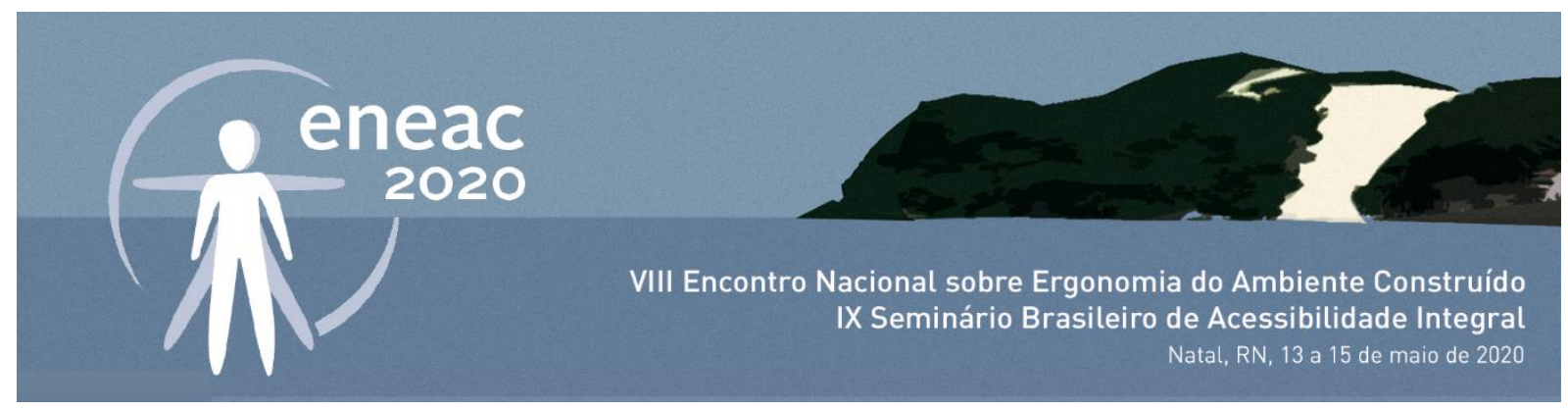

Tecnológico (CNPq) pelo auxílio financeiro que possibilitou a dedicação integral ao projeto de pesquisa. Nosso agradecimento aos educadores do curso de pós-graduação em Design pela colaboração com o desenvolvimento da pesquisa e aos colegas estudantes pela contribuição enquanto complementares no trabalho.

\section{REFERÊNCIAS}

ABERGO - Associação Brasileira de Ergonomia. O que é Ergonomia? Disponível em: <http://www.abergo.org.br/internas.php?pg=o_que_e_ergonomia>. Acesso em: 01 dez 2019.

BITTENCOURT, Fábio. Ergonomia e Conforto Humano. Uma Visão da Arquitetura, Engenharia e Design de Interiores. 2aㅡ. Ed. Rio de Janeiro: RioBooks, 2017.

IEA - International Ergonomics Association. Definition and Domains of Ergonomics. Disponível em: <https://www.iea.cc/whats/index.html>. Acesso em 01 dez. 2019.

INEP - Instituto Nacional de Estudos e Pesquisas Educacionais Anísio Teixeira. Estatísticas da Educação Superior 2018. Disponível em: <http://portal.inep.gov.br/web/guest/sinopses-estatisticas-da-educacao-superior>. Acesso em: 27 nov. 2019.

SILVA, José Carlos Plácido da; PASCHOARELLI, Luis Carlos; LUCIO, Cristina do Carmo; ALVES, Silvana Aparecida; RAZZA, Bruno Montanari. Trajetória da Ergonomia no Brasil: aspectos expressivos da aplicação em design. In: SILVA, José Carlos Plácido da; PASCHOARELLI, Luis Carlos. A evolução histórica da ergonomia no mundo e seus pioneiros. São Paulo: Cultura Acadêmica, 2010, p.91-103.

MORAES, Anamaria de; SOARES, Marcelo Mário. Ergonomia no Brasil e no mundo: um quadro, uma fotografia. Rio de Janeiro: Abergo, 1989.

PANERO, Julius; ZELNIK, Martin. Dimensionamento Humano para Espaços Interiores: Um Livro de Consulta e Referencia para Projetos. Barcelona: Editorial Gustavo Gili,2002.

SILVA, José Carlos Plácido da; PASCHOARELLI, Luis Carlos. Design Ergonômico: estudos e aplicações. São Paulo: Canal 6, 2013.

SOARES, Marcelo Marcio; MARTINS, Laura Bezerra. Design universal e ergonomia: uma parceria que garante acessibilidade para todos. In: ALMEIDA, A. T.; SOUZA, F. M. C. Produção e competitividade: aplicações e inovações. Recife: Editora UFPE, 2010, p.127-156.

VASCONCELOS, Christianne Falcão e. VILLAROUCO, Vilma. SOARES, Marcelo Marcio. Contribuição da psicologia ambiental na análise ergonômica do ambiente construído. Recife: Ação Ergonômica, vol.5. Disponível em: <http://www.abergo.org.br/revista/index.php/ae/article/view/92>. Acesso em: 01 dez. 2019.

VILLAROUCO, Vilma. O que é um ambiente ergonomicamente adequado? São Paulo: I Conferência Latino-Americana de construção sustentável, 2004. Disponível em:

<ftp://ip20017719.eng.ufjf.br/Public/AnaisEventosCientificos/ENTAC_2004/trabalhos/PAP007 0d.pdf>. Acesso em: 02 dez. 2019. 